\title{
Mating success and mating behaviour of the aphid, Myzus persicae (Hemiptera: Aphididae)
}

\author{
HeLen M. DOHERTY and Dinah F. HALES \\ Department of Biological Sciences, Macquarie University, NSW, 2109, Australia; e-mail: dhales@rna.bio.mq.edu.au
}

Key words. Myzus persicae, aphid, mating success, mating behaviour, translocation, androcyclic, age

\begin{abstract}
In this study, aspects of the reproductive performance and behaviour of male Myzus persicae (Sulzer) (Hemiptera: Aphididae) were investigated. We report that males of clones possessing an autosomal 1,3 translocation conferring insecticide resistance show a weak trend for a reduction in reproductive potential. Clones with the translocation that can produce males but no mating females (androcyclic clones) did not have an additional disadvantage. The age of virgin males and females affected mating success. Young males and females, 0-5 days old, were the most successful with respect to the number of females mated and number of eggs produced. There was a decline in reproductive potential after 9-10 days into adult life for males and after 4-5 days for females. Mating behaviour was observed in the laboratory and described. Some pre-copulatory stroking behaviour by the fore and hind legs of the male was observed. Females occasionally walked in copula sometimes resulting in the disengagement of the male before the termination of mating. Average mating duration in the experimental conditions was $10.5 \pm 4.0$ minutes and both males and females readily mated more than once.
\end{abstract}

\section{INTRODUCTION}

Little information is available on mating behaviour of aphid species. For example it is unknown how many females a male will mate with or whether reproductive success varies with the age of the male and female. Dagg \& Scheurer (1998) described the sexual behaviour of three lachnines, Cinara cuneomaculata, C. laricis, Lachnus roboris, and an aphidine, Brachycaudus helichrysi. They described the differing mating behaviour of each species and suggested that lachnine males used pheromones to mark mated females and did not attempt to mate with a marked female. Eisenbach \& Mittler (1987) found that sex pheromone production and release by the female was terminated shortly after mating in the aphid, Schizaphis graminum, and that this decreased secondary matings. The duration of copulation has been determined for a limited range of aphid species (Eisenbach \& Mittler, 1987; Gupta \& Thakur, 1993; Guldemond et al., 1994).

We investigated whether Myzus persicae (Sulzer), the ecconomically important green peach aphid, has similar patterns of mating behaviour. Clones that produce males only (androcyclic) and clones that produce both sexes (holocyclic), with and without an autosomal 1,3 translocation (Blackman et al., 1978), were used to determine differences in male sexual success. Previous studies have found that androcyclic males have a reduced egg hatching rate (Blackman, 1972; Dedryver et al., 1998). Similarly the translocation, which is associated with insecticide resistance through amplification of genes increasing the production of esterases, appears to reduce fitness and the aphid's ability to reproduce sexually (Devonshire et al., 1998). Because chromosomes in aphids are holocentric, balanced translocated or fragmented complements can pass successfully through both mitosis and meiosis (Blackman, 1987). However, reduced fitness may occur because half the gametes will be deficient or duplicative for the simple translocation. It is hypothesised that translocated androcyclic clones may have further reduced reproductive success. This project addresses the following specific questions related to male reproductive biology and behaviour. How many females can a male mate with successfully? Are androcyclic and translocated males less successful? Is male activity dependent on male and female age? Finally, what is the mating behaviour of M. persicae?

\section{MATERIALS AND METHODS}

\section{Aphid clones, production of males and mating females}

Laboratory clones of the aphid species, Myzus persicae (Sulzer), were maintained in synchronous parthenogenetic culture on cabbage seedlings (Brassica oleracea L. var Early Jersey Wakefield), a secondary host plant, at $20^{\circ} \mathrm{C}$ and a light regime of 16L : 8D. The holocyclic aphid clones used in the experiments were collected from populations on the primary host in spring 1998 in Bathurst (clones 31, 39, 41), localities in or near Hobart $(23,47,56)$, and from secondary hosts in Canberra (66, 68), Australia. Clone 03, collected from lupin in Western Australia in 1992, is an androcyclic clone with the A1,3 translocation. All other clones are karyotypically normal except clone 23, which also has the A1,3 translocation.

Males and mating females were produced by transferring young adult parthenogenetic females from short to long night conditions, $10 \mathrm{~L}$ : $14 \mathrm{D}$ at $15^{\circ} \mathrm{C}$, and collecting offspring born during the first 2-3 days. When adult, these offspring produce first gynoparae (mothers of mating females), and then males (see Hales et al., 1989). On reaching adulthood, the gynoparae were placed in groups of three on fresh seedlings to produce the mating females (oviparae). Males and females were reared in equal aged groups. Only virgin oviparae and virgin males were used in experiments. 
TABLE 1. Mean number of females mated (out of 10) and eggs fertilised by single males of four $M$. persicae clones with different genetic and life history traits. Standard deviations are given in brackets.

\begin{tabular}{|c|c|c|c|c|c|}
\hline $\begin{array}{l}\text { Male } \\
\text { clone }\end{array}$ & Description & $\mathrm{N}$ & $\begin{array}{l}\text { Range of females } \\
\text { mated }(/ 10)\end{array}$ & $\begin{array}{l}\text { Mean number of } \\
\text { females mated } \\
\text { (sd) }\end{array}$ & $\begin{array}{l}\text { Mean number of } \\
\text { eggs fertilised per male } \\
\text { (sd) }\end{array}$ \\
\hline 03 & Translocated/androcyclic & 5 & $0-8$ & $4.80(3.27)$ & $34.00(21.27)$ \\
\hline 23 & Translocated/holocyclic & 5 & $0-8$ & $4.20(3.19)$ & $24.00(25.73)$ \\
\hline 31 & Normal/holocyclic & 4 & $7-8$ & $7.75(0.50)$ & $49.75(15.48)$ \\
\hline 54 & Normal/holocyclic & 4 & $1-9$ & $6.00(3.56)$ & $32.25(18.84)$ \\
\hline
\end{tabular}

\section{Experimental design}

\section{Number of females mated per male}

Single males of each of the translocated androcyclic (clone 03), translocated holocyclic (23), and normal holocyclic clones $(31,56)$, were each placed with groups of ten females of a single normal holocyclic clone $(31,41,54,68,23$; replication involved a different clone of female) on a cabbage seedling. Seedlings were enclosed by a cylindrical perspex cage $(38 \mathrm{~mm}$ diameter, $82 \mathrm{~mm}$ depth) with a mesh top. All aphids were one to two day old adults. There were five replicates of the translocated clones, and four replicates of the normal clones. After seven days, the ten females were separated into small petri dishes $37 \mathrm{~mm}$ diameter, $11 \mathrm{~mm}$ depth) with a cabbage seedling leaf or peach twig (distributed equally per experimental group) for oviposition. Primary and secondary hosts were provided to check whether oviposition rates were reduced in absence of the primary host (the normal substrate for oviposition). Females were removed and preserved in 100\% Analytical Reagent grade ethanol one week later. Fertilised (black) and unfertilised (green or brown) eggs in the petri dishes and the experimental cages were counted two weeks after the females had been removed. Mating success was determined by the production of fertilised eggs.

\section{Effect of male and female age}

Experiment 1. To achieve a range of ages of males and females, three successive crops of five holocyclic clones (clones $31,39,47,66,68$ ) were reared under short day conditions, nine days apart. As time from induction and growth rates varied between males and females, the series of classes achieved were optimal for the males $(0-1,4-5,9-10,13-14 \mathrm{~d})$ but incomplete for the females $(0-1,4-5,18-19 d)$. Males of each of the five clones were not available across all age classes. From the available clones (including 31,39, 47, 66), single males of each age class were placed in cages with five females (one of each of the five clones) for each of the three female age classes. There were five replicates of each age class combination. After 72 hours, males were removed and preserved, and each female was placed into a separate petri dish with a peach twig for oviposition Females were removed and fertilised eggs counted as above.

Experiment 2. As the age classes of females were incomplete for the above experiment, a subsequent experiment was undertaken with females of ages $8-10,10-12,12-14,14-16$, and 16-18 days. Females (clones 41 and 68) of these age classes were mated under the same conditions as above to young males (clones 31 and 47), 4-5 day old for the first three female age groups (10 replicates) and 7-9 days old for the last two (six replicates).

\section{Mating behaviour}

To investigate male and female mating behaviour, and mating duration, ten male/female pairs of virgin aphids ( $3 \mathrm{~d}$ old) were observed throughout the light period (10 hours). Each pair of aphids was placed in a small petri dish with a cabbage leaf and a peach twig. Behaviour was recorded every 15 minutes in an airconditioned room at about $22^{\circ} \mathrm{C}$. Behaviour categories were mating, active, feeding, and passive. Aphids were recorded as active if they were walking. Passive behaviour was recorded if the aphid was motionless on the petri dish. Mating behaviour was observed throughout the daylight hours and observations recorded including copulation duration to the nearest 30 seconds for 20 mating observations viewed from beginning to end (i.e. a sample size of 20). Other matings, not observed for their duration, could not be included in the data set.

To complement the above experiments on the effect of age on fertility, these observations were repeated for 14 day old females with 2 day old males.

\section{Analysis}

Mating success was analysed with an analysis of variance (ANOVA) or appropriate non-parametric test (Kruskal-Wallis) using the statistical package Statistica (StatSoft, 1995). Tests were conducted to determine differences in the mean number of females mated and the number of fertilised eggs produced. For the effect of male and female age a two-way ANOVA was used with age of males and females as the independent variables. Where a statistically significant result was obtained, multiple t-tests were performed using the Scheffe test (StatSoft, 1995). Assumptions of normality and homogeneity of variance were checked and are specified when assumptions were not met. ANOVAs however, are reasonably robust with violations of these assumptions (StatSoft, 1995).

\section{RESULTS}

\section{Number of females mated per male}

The clones with the A1,3 translocation showed a slight trend towards a reduced mating success with an average of less than five of the ten females producing fertilised eggs (Table 1). The translocated androcyclic clone (clone 03) performed marginally better than the translocated holocyclic clone (clone 23). The normal holocyclic clones successfully mated with an average of six or more females but the difference between normal and translocated was not significant (Kruskal-Wallis: $\mathrm{H}_{3}, 18=4.42$, $\mathrm{p}=0.22$ ). As a large number of eggs were oviposited in the experimental cage before the division of the females into separate petri dishes, analysis on the number of eggs fertilised by each male was also performed. The mean number of eggs fertilised by males did not differ significantly among the clones (ANOVA: $\mathrm{F}_{3,14}=1.12, \mathrm{p}=$ $0.37)$.

The data are characterised by large ranges and variance for each of the clones. Only males of the clone 31 had a consistent mating success of seven or eight females and 
TABLE 2. Average number of females successfully mated and average number of eggs (in brackets) produced as a result of matings between single males and five females of different age classes. Data in italics are from the second age experiment (see text).

\begin{tabular}{|c|c|c|c|c|c|c|c|c|}
\hline \multirow[b]{2}{*}{ Male age } & \multicolumn{8}{|c|}{ Female age } \\
\hline & $0-1$ days & 4-5 days & $8-10$ days & $10-12$ days & $12-14$ days & 14-16 days & $16-18$ days & 18-19 days \\
\hline $0-1$ days & $\begin{array}{c}3.6 \\
(9.4)\end{array}$ & $\begin{array}{c}2.4 \\
(6.4)\end{array}$ & $=$ & $=$ & $=$ & $=$ & $=$ & $\begin{array}{c}0 \\
(0)\end{array}$ \\
\hline 4-5 days & $\begin{array}{c}2.8 \\
(6.2)\end{array}$ & $\begin{array}{c}2.6 \\
(6.2)\end{array}$ & $\begin{array}{c}0.7 \\
(1.2)\end{array}$ & $\begin{array}{l}0.4 \\
1.6\end{array}$ & $\begin{array}{c}0.3 \\
(3.3)\end{array}$ & $=$ & $=$ & $\begin{array}{c}0 \\
(0)\end{array}$ \\
\hline 7-9 days & - & - & $=$ & $=$ & $=$ & $\begin{array}{l}0 \\
0\end{array}$ & $\begin{array}{c}0.2 \\
(1.2)\end{array}$ & - \\
\hline 9-10 days & $\begin{array}{c}3.2 \\
(7.2)\end{array}$ & $\begin{array}{c}2.8 \\
(8.8)\end{array}$ & $=$ & $=$ & $=$ & $=$ & $=$ & $\begin{array}{c}0.2 \\
(0.2)\end{array}$ \\
\hline 13-14 days & $\begin{array}{c}1.2 \\
(3.8)\end{array}$ & $\begin{array}{c}1.6 \\
(2.6)\end{array}$ & $=$ & $=$ & $=$ & $=$ & $=$ & $\begin{array}{c}0 \\
(0)\end{array}$ \\
\hline
\end{tabular}

produced the most eggs. There was no significant difference between peach and cabbage leaf treatments (MannWhitney: $\mathrm{U}=3894.5, \mathrm{p}=0.64, \mathrm{~N}=90$ ).

\section{Effect of male and female age}

Experiment 1. Mating success varied with age of male and female. The average numbers of females successfully mated (i.e. that produced fertilised eggs) within each of the age class combinations are given in Table 2. The highest number of females successfully mated was achieved by the $0-1$ day old males crossed with the $0-1$ day old females (average of 3.6 females mated out of five). Males of the first three age classes achieved similar rates of mating success with $0-1$ day old females. Slightly lower values occurred for the 4-5 day old females, while the 13-14 day old males and 18-19 day old females showed a distinct drop in mating success. In a two-way ANOVA, male age was not significant $\left(\mathrm{F}_{3,48}=2.44, \mathrm{p}=\right.$ $0.08)$ while female age was significant $\left(\mathrm{F}_{2,48}=24.62, \mathrm{p}<\right.$ 0.001 ; assumptions of normality and homogeneity of variances were not met because of the large number of zeros for the oldest females). Multiple comparisons of means determined that there were significant differences between the 18-19 day old females and the two other female age classes $(p<0.001)$.

An analysis of the numbers of eggs produced by each cross revealed similar results. Male age was not significant $\left(\mathrm{F}_{3,48}=2.13, \mathrm{p}=0.11\right)$, and female age was significant $\left(\mathrm{F}_{2,48}=19.61, \mathrm{p}<0.001\right.$; assumptions not met $)$ with the significant differences being between the oldest age class of females and the two other female age classes $(\mathrm{p}<$ 0.001 )

Experiment 2. On average less than one female was successfully mated at 8-10 days of age (range 1-3 of five). For the older age classes (10 days and older), only 0-0.5 females per male were mated successfully. Egg production, however, showed a less clear trend with the 12-14 day old class producing an average of three eggs. This average is still low by comparison with egg production for females five days old and younger. The other age classes produced less than two eggs (range 0-1.6) (Table 2).

\section{Mating behaviour}

Three day old males were primarily active (active in $39 \%$ of instantaneous observations, passive $21 \%$, feeding $19 \%$ ). In contrast, for three day old females, the majority of observations were of feeding (feeding 43\%, active $29 \%$, passive $7 \%$ ). Twenty-one percent of the observations were of mating. Mating occurred throughout the observation period (10 daylight hours), with at least one pair of aphids mating at all observation times.

For males and older females the number of observations for each behaviour were different (Chi-squared analysis on counts; males: $\chi^{2}=21.0, p<0.001$; females: $\left.\chi^{2}=66.5, p<0.001\right)$. However males remained primarily active and females primarily feeding (males: active $33 \%$, feeding $31 \%$, passive $24 \%$; females: feeding $48 \%$, passive $26 \%$, active $14 \%$ ). Differences detected were a reduction in the frequency of mating, with $12 \%$ of observations recorded as mating; also males were observed feeding more often, and older females were less active and more often observed as passive. No patterns were detected in the frequency of mating throughout the 10 hours.

Females attract males by the release of pheromones from large numbers of small glands on the tibia of the hind leg (Pettersson, 1970; Hardie et al., 1996). The release of pheromones may be accompanied by lifting of the abdomen and waving of hind legs. This display seemed more prevalent among older females but could not be quantified in the context of the experiment.

As no differences between age groups were detected for mating behaviour the results were combined. Hence observations are approximately out of 40 . Mating behaviour was initiated as the male approached from any direction and climbed on top of the female, with all legs on the female. The male then orientated into position sometimes turning around up to 360 degrees ( 2 observations). This process usually took from $10-45$ seconds (40 observations). Males stroked the female with fore and hind legs. Once in position no more stroking occurred. Most females lifted their abdomen slightly as the male curled his abdomen down. Copulation then proceeded, lasting an average $10.5 \pm 4.0$ minutes (40 observations) and ranging from 5 to 20 minutes. The female sometimes walked car- 
rying the male on her back (minimum 10 observations) This was evident especially with the younger females. The female sometimes began to walk before the termination of mating ( 6 observations). This eventually resulted in the disengagement of the male. Alternatively, if the female was passive the male sometimes remained on the female's back for a short period of time after disengaging the genitalia (2 min maximum; 12 observations). Once mating was completed the male climbed off to the side or forward and walked away from the female. There was no evidence of the male marking the female.

In six recorded observations the male attempted copulation within a few minutes of a previous mating with the female. This second mating was either deemed successful (lasting $>5$ minutes) or lasted approximately 45 seconds (three observed occasions) before the male disengaged.

\section{DISCUSSION}

\section{Factors affecting mating success}

In accordance with findings of Devonshire et al. (1998), this study showed a slight trend for translocated clones to have a reduced reproductive success. However, the differences detected do not indicate that translocated clones uniformly mate with fewer females, but rather males have a greater variation in success. Some males were highly successful while others unsuccessful. Given this high variance, caution must be exercised as the sample size is small. The trends found may be interpreted as the result of differences generated by the unbalanced nature of the gametic products. Because meiosis is achiasmate, and no recombination occurs in the males (Sloane et al., 2001), further reduction in viability because of crossing over in meiosis is not expected.

The translocated androcyclic clone used in this study did not have an additional reduction in reproductive success for the androcyclic condition. It is possible, however, that while egg production is not affected, reduced egg hatching may occur for androcyclic males as found for Sitobion (Dedryver et al., 1998).

This experiment indicated that a range of $0-9$ of 10 females can be successfully mated by a single male within a period of a week. On average, more than six females were mated by each male of the holocyclic clones. However, mating success was determined by the production of fertilised eggs when separated after seven days. Some females may have been classified as unmated but may have produced eggs before separation. Others have reported that males are able to inseminate a considerable number of females in 24 hours (e.g. Cryptomyzus galeopsidis and C. maudamanti an average of 7.9 and 8.9 respectively) (Guldemond et al., 1994).

This study found that reproductive potential began to decline after 9-10 days for virgin males. At 13-14 days, mating success was reduced by up to $62 \%$. Conversely, reproductive success for virgin females declined after 4-5 days, with a reduction of $70 \%$ at $8-10$ days of age. Such females become swollen with unlaid eggs although some laid unfertilised eggs. In contrast to our finding that the youngest females were most likely to be successfully mated, Wipperfürth \& Mittler (1986) found that 3-6 day old greenbug females were most successful.

\section{Mating behaviour}

Observations of the daily activities of $M$. persicae in a laboratory environment revealed that males were primarily active (as the searching sex locating the females), and females spent the majority of their time feeding. Copulation duration averaged $10.5 \mathrm{~min}$ (range, 5-20), and was intermediate in time compared with average duration reported for other aphid species: Schizaphis graminum, 6.9 min (Eisenbach \& Mittler, 1987); Cryptomyzus ribis, $21.2 \mathrm{~min}$, C. galeopsidis, $8.9 \mathrm{~min}$ (Guldemond et al., 1994); Brachycaudus helichrysi, $2.8 \mathrm{~min}$ (Gupta \& Thakur, 1993). While dissections were not performed to confirm successful mating for $M$. persicae (as in Gupta \& Thakur, 1993; Guldemond et al., 1994;), the shortest encounter beyond 60 seconds was five minutes and therefore a copulation duration of five minutes or longer was assumed to be a successful mating event. However, Guldemond et al. (1994) showed that copulation did not always result in the transfer of spermatozoa especially in interspecific matings. While all the matings studied by us were intraspecific, unpublished data from this laboratory suggest that some clones may have diminished mating success.

Mating was observed to occur throughout the daylight hours. Behaviour was not observed in the dark. However Eisenbach \& Mittler (1987) and Guldemond \& Dixon (1994) reported that Schizaphis graminum and Cryptomyzus, respectively, do not call in the dark.

Older females were observed to exhibit a pheromone release display more often than young females, but mating observations were lower. In other aphid species an increase in pheromone release with age has been reported (Eisenbach \& Mittler, 1987; Thieme \& Dixon, 1996) up to an age of six and eight days, respectively. Given the increased release of pheromone it is unclear why fewer mating events were recorded for the older $M$. persicae females. This behavioural observation may explain in part the reduced fertilisation success in older females identified above.

Attempted copulations lasting under 60 seconds were observed three times: all took place a couple of minutes post-mating. The male may have become disengaged through female non-cooperation. The females were occasionally seen to walk in copula sometimes resulting in the disengagement of the male. Explanations of this behaviour may include the following two interpretations for other aphid species. Walking in copula occurs in the species Tetraneura nigriabdominalis: the walking behaviour was interpreted as the female seeking refuge for oviposition (Galli, 1998). Guldemond et al. (1994) reported that females sometimes showed a lack of cooperation by walking away, vigorously lifting their abdomen, trying to push or kick the male away or raising their body perpendicular to the leaf surface. This tended to occur for interspecific matings. $M$. persicae females when walking in copula might therefore be either seeking oviposition sites or trying to reject the male. The latter would be an 
example of female choice (e.g. Eberhard, 1994; Birkhead, 1998), and may be important in the context of differential success of males (to be published separately).

No unusual courtship behaviour was observed. Evidence of marking with the aedeagus by the male as described by Dagg \& Scheurer (1998) for lachnine species was not observed for $M$. persicae. It was hypothesised that by marking females, males would be able to determine the mating status of females. In this study multiple copulations for both sexes occurred. This has been shown to increase the number of eggs deposited (Eisenbach \& Mittler, 1987). M. persicae males stroked the female while positioning for mating. Stroking post mating and the stroking behaviour of $B$. helichrysi during mating (Dagg \& Scheurer, 1998) were not observed.

The laboratory environments used are not equivalent to the field environment. Because of practical constraints males and females were maintained on their secondary host. No significant difference in oviposition was detected between females given peach twigs or cabbage leaves. However, the lack of the primary host is known to affect aspects of behaviour in other species, e.g. reduced release of pheromone by females when not on the primary host (Guldemond \& Dixon, 1994). Also, the confined space of a small petri dish may allow saturation of the environment with pheromone, disrupting normal patterns of release and possibly influencing male behaviour.

In conclusion, we have shown that androcycly does not reduce male reproductive performance in $M$. persicae, and that reproductive success varies with adult age in both sexes. No evidence of marking of mated females was noted.

ACKNOWLEDGEMENTS. This work was supported by an Australian Research Council Large Grant to DFH. Key Centre for Biodiversity and Bioresources publication number 355 .

\section{REFERENCES}

BIRKHEAD T.R. 1998: Cryptic female choice: Criteria for establishing female sperm choice. Evolution 52: 1212-1218.

BlackMan R.L. 1972: The inheritance of life-cycle differences in Myzus persicae (Sulz.) (Hem.: Aphididae). Bull. Entomol. Res. 62: 281-295.

BlaCKMAN R.L. 1987: Reproduction, cytogenetics and development. In Minks A.K. \& Harrewijn P. (eds): Aphids, their Biology, Natural Enemies and Control, Vol $2 A$. Elsevier, Amsterdam, pp. 163-195.

Blackman R.L., Takada H. \& Kawakami K. 1978: Chromosomal rearrangement involved in insecticide resistance of Myzus persicae. Nature Lond. 271: 450-452.

DAGG J. \& SCHEURER S. 1998: Observations in some patterns of the males' sexual behaviour of certain aphid species indicate the existence of male marking pheromones. In Nieto Nafría,
J.M. and Dixon A.G. (eds): Aphids in Natural and Managed Ecosystems. Secretariado de Publicaciones, Universidad de León, Leon (Spain), pp. 167-171.

Dedryver C.A., Le Gallic J.R., Gauthier J.P. \& Simon J.C 1998: Life-cycle of the cereal aphid Sitobion avenae F.: Polymorphism and comparison of life-history traits associated with sexuality. Ecol. Entomol. 23: 123-132.

Devonshire A.L., Field L.M., Foster S.P., Moores G.D., WilLIAMSON M.S. \& BLACKMAN R.L. 1998: The evolution of insecticide resistance in the peach-potato aphid, Myzus persicae. Phil. Trans. R. Soc. Lond. B 353: 1677-1684.

EBERHARD W.G. 1994: Evidence for widespread courtship during copulation in 131 species of insects and spiders, and implications for cryptic female choice. Evolution 48: 711-733.

EisenBaCh J. \& MitTler T.E. 1987: Effects of photoperiod and mating on sex pheromone production and release by oviparae of the aphid Schizaphis graminum. Physiol. Entomol. 12: 293-296.

Galli E. 1998: Mating behaviour in Tetraneura nigriabdominalis Sasaki (= akinire Sasaki) (Hemiptera: Pemphiginae). Invert. Reprod. Dev. 34: 173-176.

GuLdemond J.A. \& Dixon A.F.G. 1994: Specificity and daily cycle of release of sex pheromones in aphids: a case of reinforcement? Biol. J. Linn. Soc. 52: 287-303.

Guldemond J.A., Tigges W.T. \& DE VRIJer P.W.F. 1994: Circadian rhythm of sex pheromone production and male activity of coexisting sibling species of Cryptomyzus aphids (Homoptera: Aphididae). Eur. J. Entomol. 91: 85-89.

GuPTA P.R. \& THAKUR J.R. 1993: Sexual generation and overwintering of the peach leaf curling aphid Brachycaudus helichrysi (Kalt.) in Himachal Pradesh, India. Ann. Appl. Biol. 122: 215-221.

Hales D.F., Wellings P.W. \& ParKes R.A. 1989: Investment in gynoparae and males by Myzus persicae. Funct. Ecol. 3: $727-734$.

Hardie J., Storer J.R., Cook F.J., Campbell C.A.M., Wadhams L.J., Lilley R. \& Pearce L. 1996: Sex pheromone and visual trap interactions in mate location strategies and aggregation by host-alternating aphids in the field. Physiol. Entomol. 21: 97-106.

Pettersson J. 1970: An aphid sex attractant. I. Biological studies. Entomol. Scand. 1: 63-73.

Sloane M.A., Sunnucks P., Wilson A.C.C. \& Hales D.F. 2001: Microsatellite isolation, linkage group identification and determination of recombination frequency in the peach-potato aphid, Myzus persicae (Sulzer) (Hemiptera: Aphididae). Genet. Res. Camb. 77: 251-260.

StATSOFt 1995: Statistica: Volume I: General Conventions and Statistics I (2nd ed.). StatSoft, Inc., USA.

Thieme T. \& Dixon A.F.G. 1996: Mate recognition in the Aphis fabae complex: daily rhytm of release and specificity of sex pheromones. Entomol. Exp. Appl. 79: 85-89.

WIPPERFÜRTH T. \& MitTleR T.E. 1986: A method for hatching the eggs of the aphid Schizaphis graminum. Entomol. Exp. Appl. 42: 57-61.

Received September 3, 2001; revised January 7, 2002; accepted January 21, 2002 